\title{
Relato de caso da trajetória e tratamento em um paciente com miocardite viral
}

\author{
Case report of the trajectory and treatment in a patient with viral myocarditis \\ Reporte de caso de trayectoria y tratamiento en paciente con miocarditis viral \\ Samira Corrêa Moreira ${ }^{1 *}$, Marlucia do Nascimento Nobre'.
}

\begin{abstract}
RESUMO
Objetivo: Relatar um caso de paciente com miocardite viral, acompanhado desde seu diagnóstico em 2014 até o momento atual. Detalhamento de Caso: Paciente internado em uma unidade hospitalar em uma cidade no Amazonas, para investigação diagnóstica de miocardiopatia dilatada secundária a miocardite viral. Foi inicialmente diagnosticado com insuficiência cardíaca (IC), ao realizar angiotomografia, apresentou reação negativa ao exame, sendo encaminhado para internação, onde na admissão apresentou parada cardiorrespiratória. No período de internação foi diagnosticado com choque cardiogênico, IC aguda secundaria a miocardiopatia dilatada decorrente de miocardite viral. Após a alta, o paciente permaneceu em acompanhamento ambulatorial até os dias de hoje, apresentando evidente melhora de seu quadro clínico, recebendo atualmente a seguinte medicação: Carvedilol 25mg 12/12h; Captopril 25mg 12/12h; Espironolactona $25 \mathrm{mg} / \mathrm{dia}$. Considerações finais: O acompanhamento desse caso mostra a melhora clínica do paciente, com recuperação da função cardíaca, evidenciando que, com o tratamento adequado, foi possível contornar a doença e proporcionar melhoria na qualidade de vida ao portador de miocardite viral.
\end{abstract}

Palavras-chave: Miocardite viral, Cardiomiopatia dilatada, Tratamento de miocardite.

\section{ABSTRACT}

Objective: To report a case of a patient with viral myocarditis, followed from his diagnosis in 2014 to the present moment. Case Details: Patient admitted to a hospital unit in a city in Amazonas, for diagnostic investigation of dilated cardiomyopathy secondary to viral myocarditis. He was initially diagnosed with heart failure (HF), when performing angiotomography, he showed a negative reaction to the exam, being referred for admission, where on admission he had cardiorespiratory arrest. During hospitalization, he was diagnosed with cardiogenic shock, acute HF secondary to dilated cardiomyopathy resulting from viral myocarditis. After discharge, the patient remained in outpatient follow-up until today, showing an evident improvement in his clinical condition, currently receiving the following medication: Carvedilol 25mg 12/12h; Captopril 25mg 12/12h; Spironolactone $25 \mathrm{mg} /$ day. Final considerations: The monitoring of this case shows the clinical improvement of the patient, with recovery of cardiac function, showing that, with the proper treatment, it is possible to circumvent the disease and provide a good quality of life to the patient with viral myocarditis.

Keywords: Viral myocarditis, Dilated cardiomyopathy, Myocarditis treatment.

\section{RESUMEN}

Objetivo: Informar un caso de un paciente con miocarditis viral, seguido desde su diagnóstico en 2014 hasta el momento presente. Detalles del caso: Paciente ingresado en un hospital de una ciudad de Amazonas, para estudio diagnóstico de miocardiopatía dilatada secundaria a miocarditis viral. Inicialmente fue diagnosticado de insuficiencia cardíaca (IC), al realizar la angiotomografía presentó una reacción negativa al examen, siendo remitido para ingreso, donde al ingreso presentó parada cardiorrespiratoria. Durante el ingreso se le diagnosticó shock cardiogénico, IC aguda secundaria a miocardiopatía dilatada por miocarditis viral. Tras el alta, el paciente permaneció en seguimiento ambulatorio hasta el día de hoy, mostrando una evidente mejoría de su estado clínico, recibiendo actualmente la siguiente medicación: Carvedilol 25mg 12/12h; Captopril 25 mg 12/12 h; Espironolactona 25 mg/día. Consideraciones finales: El seguimiento de este caso muestra la mejoría clínica del paciente, con recuperación de la función cardíaca, lo que demuestra que, con el tratamiento adecuado, es posible evitar la enfermedad y proporcionar una buena calidad de vida a los pacientes con miocarditis viral.

Palabras clave: Miocarditis viral, Miocardiopatía dilatada, Tratamiento de miocarditis.

\footnotetext{
${ }^{1}$ Hospital Universitário Getúlio Vargas. Manaus - AM. *E-mail: samira.moreira@gmail.com
} 


\section{INTRODUÇÃO}

A miocardite é uma inflamação do miocárdio geralmente induzida por agentes infecciosos, principalmente virais, causa significativa de morte súbita em jovens até 40 anos e causa subjacente de cardiomiopatia dilatada (CD) (KANG N e NA J, 2019; POLLACK A, et al., 2015 e HUBER SA, 2016). Cerca de 40\% dos casos de CD estão associados a inflamação ou infecção viral (HEYMANS S, et al., 2016). Entre os mais comuns estão os enterovírus, adenovírus, parvovírus B19, herpesvírus humano 6 , citomegalovírus humano, vírus Epstein Barr, vírus da hepatite e da imunodeficiência humana (HIV) (POLLACK A, et al., 2015 e ROSE NR, 2016).

Em países desenvolvidos, as infecções virais são as causas mais frequentes, enquanto nos países em desenvolvimento etiologias como cardite reumática, doença de Chagas, complicações relacionadas ao HIV e miocardite tóxica (relacionada a medicamentos9 são relevantes (KANG N e NA J, 2019).

A miocardite viral (MV) tem uma taxa de incidência de 10 a 22 por 100.000 indivíduos. Seu padrão clínico pode variar de sintomas inespecíficos como fadiga e falta de ar a mais agressivos que imitam a síndrome coronariana aguda. Após a apresentação inicial da fase aguda, o vírus pode ser eliminado, resultando em recuperação clínica completa, mas a infecção viral pode persistir ou levar a um processo inflamatório persistente autoimune com sintomas contínuos de insuficiência cardíaca (IC). Como resultado dessas três possibilidades, o diagnóstico, prognóstico e tratamento da MV podem ser extremamente imprevisíveis e desafiadores (OLEJNICZAK M, et al., 2020).

A doença representa uma causa significativa de morte, especialmente em jovens. Após a infecção, os pacientes podem desenvolver inflamação do miocárdio, podendo ocasionar CD infecciosa, que frequentemente requer transplante (ROSE NR, 2016). Pode se manifestar em fase aguda, subaguda ou crônica e apresentar envolvimento focal ou difuso do miocárdio (KANG N e NA J, 2019).

Estudos experimentais revelaram papéis reguladores complexos para vários ácidos microribonucleicos e subtipos de células T e macrófagos (HEYMANS S, et al., 2016). Assim, a infecção viral do coração desencadeia a ativação da resposta imune antiviral do hospedeiro, caracterizada pela infiltração de células assassinas e macrófagos, seguida por linfócitos T específicos do vírus. A resposta imune funciona como uma "faca de dois gumes": a ativação inicial é benéfica para o hospedeiro limitando a disseminação viral, no entanto, uma resposta imune persistente e excessiva traz consequências danosas que contribuem para a progressão da miocardite e CD. O equilíbrio entre as influências antivirais e os efeitos deletérios sobre a função cardíaca é um determinante importante da gravidade da miocardite e da progressão para CD (FUNG G, et al., 2016).

O diagnóstico da miocardite é feito, geralmente, com base na apresentação clínica, podendo ser confirmado classicamente por biópsia endomiocárdica, através de critérios histológicos, imunológicos e imuno-histoquímicos (KANG N e NA J, 2019). Para o diagnóstico diferencial de MV versus não-viral e o diagnóstico de miocardite eosinofílica ou de células gigantes, a biópsia endomiocárdica permanece essencial, enquanto a investigação da biópsia inclui histologia, imuno-histologia e reação em cadeia da polimerase (PCR) para ácido ribonucleico (RNA) ou ácido desoxirribonucleico (DNA) viral (MAISCH B e ALTER P, 2018).

Exames complementares também podem ser úteis, como eletrocardiograma em repouso e em exercício, imagens por ecocardiografia Doppler ou ressonância magnética, além de um exame laboratorial completo com proteína $\mathrm{C}$ reativa e peptídeo natriurético tipo $\mathrm{N}$ do terminal pró-B (NTproBNP) e troponina T ou I de alta sensibilidade (MAISCH B e ALTER P, 2018).

As opções terapêuticas são limitadas para as fases aguda e crônica da miocardite, mas vários ensaios clínicos randomizados e controlados demonstraram benefício potencial com terapias imunossupressoras e imunomoduladoras (POLLACK A, et al., 2015). Todavia, Huber SA (2016) discorda, e diz que, embora histologicamente a doença geralmente esteja associada à infiltração do miocárdio com eosinófilos ou leucócitos, o uso de imunossupressão é controverso. Drogas imunossupressoras clássicas, como a ciclosporina $\mathrm{A}$ e a ciclofosfamida, não são eficazes contra todos os tipos de imunidade e os modelos experimentais demonstraram que certas formas imunopatogênicas da doença são resistentes a esses agentes. 
No intuito de acrescentar dados sobre a trajetória e o tratamento da doença, esse estudo objetivou relatar um caso clínico, acompanhado desde seu diagnóstico em 2014 até abril de 2020.

\section{DETALHAMENTO DO CASO}

No Amazonas, em 2 de julho de 2014, F.R.C.J, masculino, 34 anos, iniciou quadro de febre não aferida, odinofagia, rinorreia e mal-estar geral, evoluiu em uma semana com dispneia leve, quando procurou assistência médica, sendo medicado com sintomáticos devido ao quadro viral e recebendo alta para tratamento domiciliar. Entretanto, evoluiu com piora da dispneia, procurando novamente assistência médica, sendo solicitada angiotomografia de coronárias. Durante sua realização apresentou instabilidade hemodinâmica e necessidade de internação hospitalar em unidade de terapia intensiva (UTI).

O ecocardiograma mostrou fração de ejeção $25 \%$ e hipocinesia difusa do ventrículo esquerdo. Apresentou choque cardiogênico, tratado com droga vasoativa e inotrópico positivo (noradrenalina e dobutamina) e diurético de alça com posterior desmame e retirada após estabilidade clínica.

$\mathrm{Na}$ UTI, evoluiu com delirium e confusão mental, administrado antipsicótico, sem resposta efetiva, sendo levantada hipótese de delirium devido baixo débito cardíaco frente ao quadro clínico e disfunção cardíaca evidenciada no ecocardiograma. Iniciado tratamento para IC, com boa resposta clínica e melhora do quadro.

Em 27 de agosto de 2014 o paciente foi transferido para o segundo Hospital, onde foi mantido em tratamento, realizando exames, recebendo o diagnóstico de miocardite, provável etiologia viral, evoluindo com IC classe funcional III da Classificação funcional da New York Heart Association, Estágio C. Com evolução positiva do quadro, recebeu alta em 12 de setembro, para acompanhamento ambulatorial, com as medicações: Marevan 5mg/dia; Carvedilol 25mg 12/12h; Captopril 25mg 8/8h; Espironolactona 25mg/dia e Digoxina $0,25 \mathrm{mg} / \mathrm{dia}$.

Desde então o paciente manteve consultas regulares para acompanhamento. Na investigação da etiologia foi realizado sorologia para Epstein-Baar: Epstein-Baar/VCA IgG 67,16; Epstein-Barr/VCA IgM 0,10, constatando que o paciente foi previamente infectado pelo vírus. Ao longo do acompanhamento foram realizados ecocardiogramas anuais para avaliar a recuperação da função cardíaca, observando melhora significativa, conforme demonstrado no Gráfico 1 e Figura 1 A e B.

Observa-se no Gráfico 1 que a fração de ejeção em 14 de agosto de 2014 (internação) era de apenas $25 \%$, evoluindo lentamente ao longo da internação e tratamento, chegando a $29 \%$ em 2 de setembro, mas com melhora mais significativa após a alta hospitalar, mantendo o tratamento ambulatorial, chegando a $68 \%$ em 15 de fevereiro de 2020.

Gráfico 1 - Evolução da melhora da função cardíaca do paciente através da Fração de Ejeção (FE), desde 2014 até 2020. Resultados em porcentagem (\%).

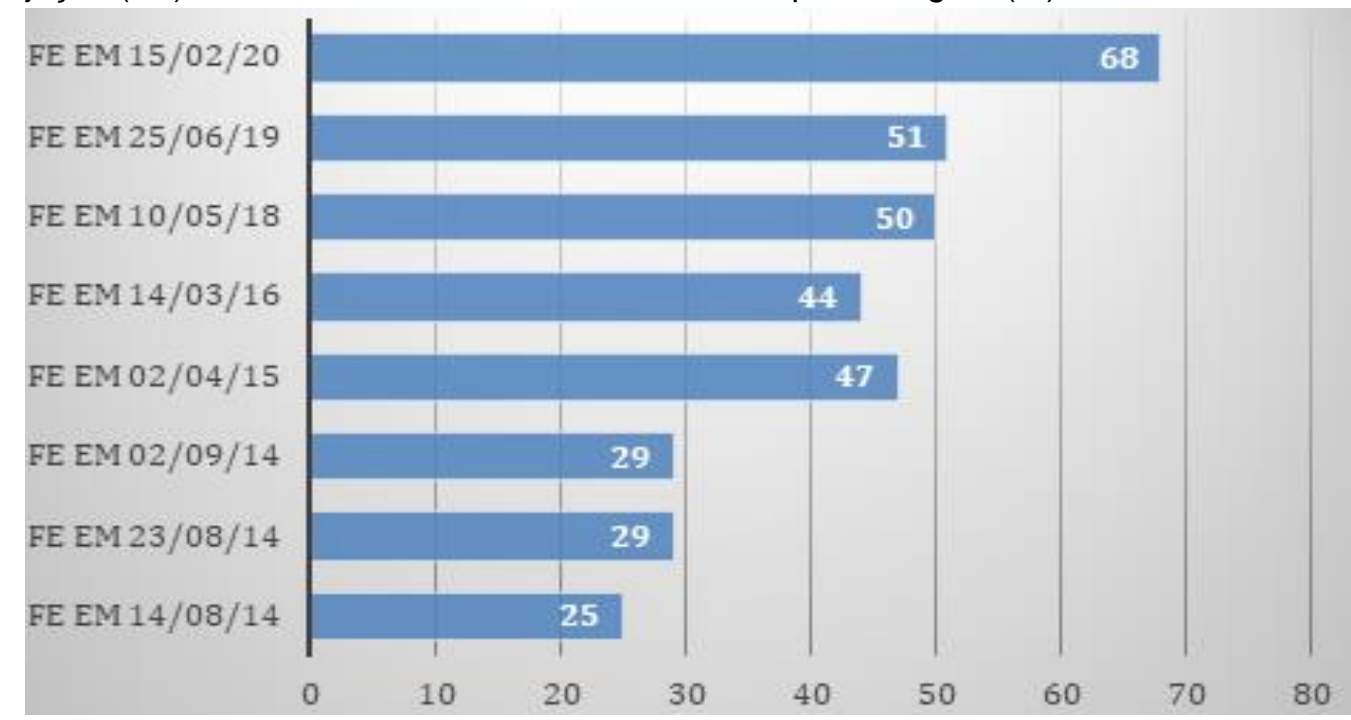

Fonte: Moreira SC e Nobre MN, 2020. 
Figura 1 - Representação dos ecocardiogramas realizado pelo paciente. A - Revela Fração de Ejeção pelo Modo M (ecocardiograma realizado no dia 14 de agosto de 2014). B - Revela Fração de Ejeção pelo Método Bidimensional (ecocardiograma realizado no dia 15 de fevereiro de 2020).
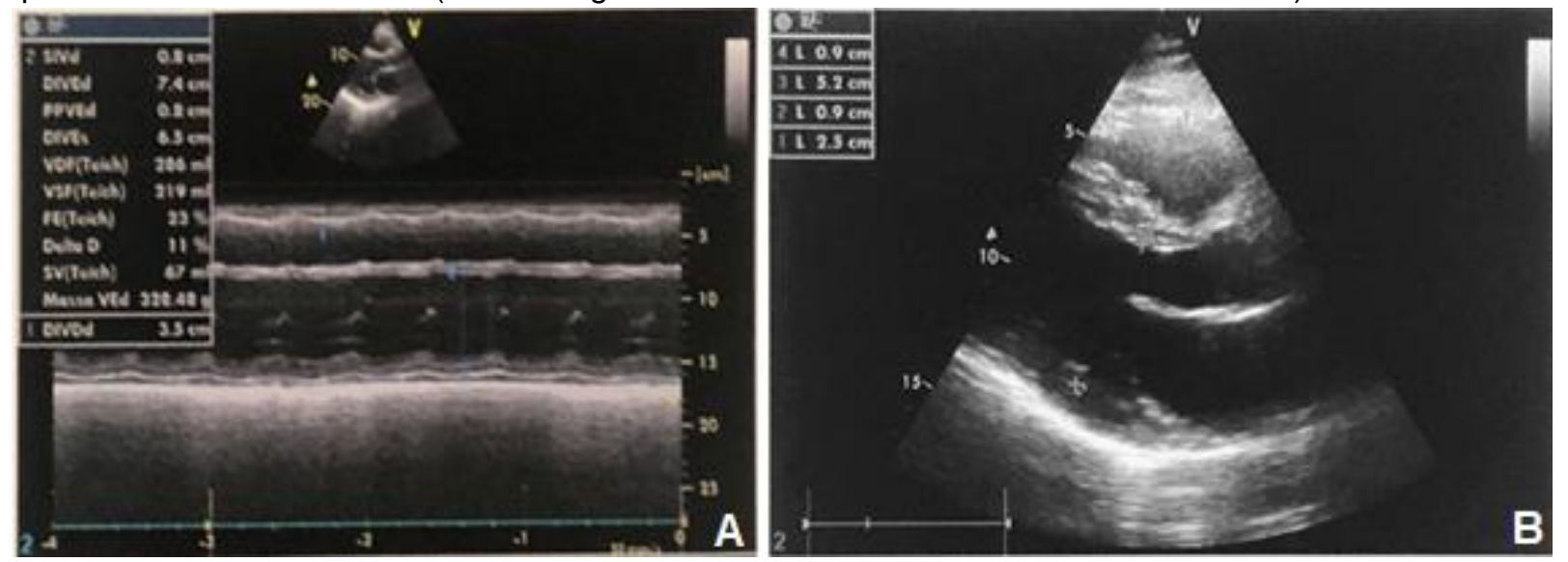

Fonte: Moreira SC e Nobre MN, 2020.

Observa-se na Figura 1 A os seguintes parâmetros: Superfície Corpórea (SC) 2.151. AO: $31 \mathrm{~mm}$. Átrio Esquerdo (AE): 53mm. DVD: 35mm. Diâmetro Diastólico Final do Ventrículo Esquerdo (DDFVE): 74mm. Diâmetro Sistólico Final do Ventrículo Esquerdo (DSFVE): 65mm. Septo: 8. Parede Posterior do Ventrículo Esquerdo (PPVE): 8. FE (t) 25\%. Massa ventricular esquerda $270 \mathrm{~g}$. Relação massa/SC: $125,54 \mathrm{~g} / \mathrm{m}$ relação volume/massa: $1,50 \mathrm{ml} / \mathrm{g}$. Volume sistólico final: $216 \mathrm{ml}$. Aumento do ventrículo esquerdo (VE) de grau importante. Disfunção sistólica do VE de grau importante. Hipocinesia difusa. Átrio esquerdo de grau moderado - volume indexado $38 \mathrm{ml} / \mathrm{m}^{2}$. Derrame pericárdico de grau leve sem repercussão hemodinâmica. Refluxo mitral de grau leve. Hipertensão pulmonar leve PSAP 40mmhg.

Já na Figura 1 B, os parâmetros foram os seguintes: SC: 2,076. Ao: 28mm. AE: 40mm. DVD: 25mm. DDFVE: 52mm. DSFVE:32. Septo: 9. PPVE: 9. FE (t) 68\%. Massa ventricular esquerda 169g. Relação massa/SC: $81,41 \mathrm{~g} / \mathrm{m}^{2}$. Relação volume/massa: $0,83 \mathrm{ml} / \mathrm{g}$. Volume diastólico final $130 \mathrm{ml}$. Volume sistólico final: $41 \mathrm{ml}$. Ecocardiograma com doppler de fluxo em cores normal em repouso. Portanto, pode-se observar melhora significativa da quantificação das cavidades cardíacas e função sistólica, em relação aos exames anteriores realizados.

O paciente segue em acompanhamento ambulatorial, recebendo as seguintes medicações: Carvedilol $12,5 \mathrm{mg}$ 12/12h e Captopril 25mg 12/12h. Permanece com queixa de cansaço leve as atividades moderadas e já em desmame de terapia medicamentosa.

\section{DISCUSSÃO}

Conforme alertado por Pollack A, et al. (2015) e Huber SA (2016), a miocardite é uma causa significativa de morte súbita inesperada em jovens com menos de 40 anos de idade, o que quase ocorreu com esse paciente, que foi internado aos 29 anos em decorrência de complicações da doença, chegando a sofrer parada cardiorrespiratória.

Entre os principais sintomas, Kang $\mathrm{N}$ e $\mathrm{Na} \mathrm{J}$ (2020) citam a fadiga generalizada, mal-estar, dor no peito, IC, choque cardiogênico, arritmias e parada cardíaca, e o paciente desse estudo apresentou todos estes sintomas. Segundo Fung G, et al. (2016), a identificação e validação de estratégias de manejo e terapêuticas mais eficazes para miocardite são críticas para a prevenção e interrupção de doenças musculares cardíacas que se manifestam como IC e morte súbita. As três principais abordagens para o tratamento da MV são: inibição de patógenos, modulação imunológica e terapia para IC.

Nesse caso, foi escolhida a terapia para IC, e Fung G, et al. (2016) recomendam os seguintes medicamentos: inibidores da enzima de conversão da angiotensina, bloqueadores dos receptores da angiotensina II, bloqueadores $\beta$, antagonistas da aldosterona e bloqueadores dos canais de cálcio. No 
paciente do estudo vêm sendo utilizados, com sucesso: Carvedilol (bloqueador não seletivo $\beta \alpha$ ); Captopril (inibidor da enzima conversora da angiotensina I); e Espironolactona (antagonista da aldosterona).

Para Maisch B e Alter P (2018), em caso de miocardite e cardiomiopatia, um tratamento etiologicamente direcionado é a melhor opção além da terapia para IC. Os pré-requisitos são biomarcadores não invasivos e invasivos, incluindo biópsia endomiocárdica e PCR em agentes cardiotrópicos. Segundo Heymans S, et al. (2016), estudos experimentais recentes revelam papéis reguladores complexos para ácidos microrribonucleicos, subtipos de células T e macrófagos. No caso relatado não foi escolhida essa abordagem, pois a terapia para IC gerou resultados satisfatórios.

Outros tratamentos vêm sendo testados, como no estudo de Shao L, et al. (2016), onde examinaram a eficácia terapêutica da coenzima Q10 e da trimetazidina no tratamento da MV, por possuírem efeitos antioxidantes e anti-inflamatórios. Confirmou-se o efeito benéfico da Q10 e da trimetazidina individualmente, mas demonstrou um efeito superior da combinação das terapias na fração de ejeção do VE e marcadores bioquímicos de dano miocárdico na MV aguda.

Xu P, et al. (2018) investigaram os efeitos clínicos do sulfonato de sódio de tansinona IIA combinado com trimetazidina e levocarnitina no tratamento da MV aguda. Utilizaram 86 pacientes, selecionados e divididos aleatoriamente em grupo controle $(n=43)$ e grupo de observação $(n=43)$. Concluíram que o sulfonato de sódio de tansinona IIA combinado com trimetazidina e levocarnitina tem efeitos curativos definitivos no tratamento de pacientes com MV aguda, o que pode aliviar a lesão miocárdica com maior segurança e efetivamente mitigar a resposta inflamatória em pacientes, sendo um resultado de grande significado clínico.

Para casos de MV fulminante, Wang D, et al. (2018) informam que a Declaração de Consenso de Especialistas da Sociedade Chinesa de Cardiologia sobre o Diagnóstico e Tratamento da Miocardite Fulminante, com base nos dados de seu ensaio clínico, descrevem um novo regime de tratamento denominado regime de tratamento abrangente baseado em suporte de vida. O conteúdo principal deste tratamento inclui: (i) suporte mecânico de vida (aplicações de respiradores mecânicos e sistemas de suporte circulatório, incluindo bomba de balão intra-aórtica e oxigenação por membrana extracorpórea); (ii) modulação imunológica usando doses suficientes de glicocorticoide e imunoglobulinas; e (iii) reagentes antivirais usando inibidor de neuraminidase. Segundo eles, a aplicação adequada deste regime de tratamento pode e tem ajudado a salvar a vida de muitos pacientes com miocardite fulminante.

Segundo Wang Y, et al. (2020), a N-acetilcisteína (NAC) é um antioxidante amplamente utilizado e, em seu estudo, ela aliviou significativamente a lesão miocárdica causada por Coxsackievirus B (CVB) tipo 3 sob condição in vivo. O tratamento com NAC suprimiu simultaneamente a replicação viral e a resposta inflamatória no miocárdio e na cultura de células. O mecanismo antiviral e anti-inflamatório do NAC, embora independente de sua propriedade antioxidante, depende de sua inibição na ativação da caspase-1. Além disso, o NAC promove a degradação da procaspase-1 por meio do sistema ubiquitina proteassoma, que contribui ainda mais para a regulação negativa da caspase-1. NAC também inibe a atividade de proteases virais. Ao somar essas características em conjunto, este estudo mostrou que o NAC exerce um potente efeito anti-CVB e antiinflamatório através do direcionamento da caspase-1. Os pesquisadores recomendam o NAC como um valioso agente para miocardite viral por CVB.

Schultheiss HP, et al. (2016) basearam-se no fato de que a terapia para IC sintomática não afeta uma causa infecciosa subjacente e não pode prevenir a lesão tecidual induzida por vírus em pacientes com cardiomiopatia viral crônica, e hipotetizaram que o tratamento antiviral administrado a tempo é necessário para melhorar ou abolir a progressão do dano miocárdico associado ao vírus. Utilizaram 143 pacientes com sintomas de IC e confirmação baseada em biópsia miocárdica, aleatoriamente designados para tratamento duplo-cego, onde receberam placebo ou interferon beta-1b (IFN- $\beta-1 b)$ por 24 semanas. Concluíram que 0 tratamento imunomodulador com IFN- $\beta$-1b é uma opção de tratamento bem tolerada e segura, levando à eliminação efetiva do vírus ou redução da carga viral em pacientes com cardiomiopatia viral crônica.

Para Maisch B (2019), embora a inflamação do miocárdio possa se resolver espontaneamente, o tratamento específico direcionado à etiologia causal é necessário. Nesse caso, para miocardite fulminante, 
aguda e crônica autorreativa sem persistência viral, o tratamento imunossupressor pode salvar vidas, enquanto para cardiomiopatia inflamatória viral, o tratamento com imunoglobulinas intravenosas pode resolver a inflamação e frequentemente erradicar o vírus. Sendo assim, um tratamento personalizado deve ser adaptado dentro do intervalo de tempo desde a infecção até a resposta inata e adaptativa.

Sobre o prognóstico, Chen WH, et al. (2019) afirmam que a presença de um vírus não piora o prognóstico em longo prazo dos pacientes com suspeita de miocardite ou CD. No entanto, pacientes com diagnóstico viral positivo não submetidos a tratamento específico ou que realizaram biópsia do ventrículo direito tiveram pior prognóstico. Assim, sugere-se que a terapia antiviral ativa pode melhorar o prognóstico de pacientes com vírus positivo com cardiomiopatia. Ao mesmo tempo, uma biópsia miocárdica precoce para descartar a presença de infecções virais no miocárdio ajudará a avaliar o prognóstico e ajustar as estratégias de tratamento ao considerar miocardite ou cardiomiopatia no caso de IC inexplicada.

Sabe-se que homens são diagnosticados com miocardite com mais frequência e têm um prognóstico pior que mulheres, o que se atribui à uma resposta fibrótica mais pronunciada (HEYMANS S, et al., 2016). Uma apresentação da doença com dor no peito ou IC Congestiva geralmente indica um prognóstico ruim, pois o prognóstico a longo prazo se correlaciona com a gravidade de sua apresentação inicial (KANG N e NA J, 2019).

Pacientes com função preservada do VE no diagnóstico têm um bom prognóstico, enquanto pacientes com disfunção grave de VE ou biventricular com colapso hemodinâmico tendem a apresentar prognóstico ruim. Outros marcadores clínicos que podem prever um prognóstico ruim incluem histórico de síncope, duração prolongada da QRS, bloqueio de ramo esquerdo, hipertensão pulmonar e sintomas de IC classe III ou IV (POLLACK A, et al., 2015).

O acompanhamento desse caso mostra sua melhora clínica com tratamento direcionado para IC, principalmente sobre a recuperação da função cardíaca, o que se verifica através dos ecocardiogramas realizados. Isso mostra que, com o tratamento adequado, é possível contornar a doença e proporcionar uma boa qualidade de vida ao portador de MV.

\section{REFERÊNCIAS}

1. CHEN WH, et al. Long-term prognosis of suspected myocarditis and cardiomyopathy associated with viral infection of the myocardial tissue: a meta-analysis of cohort studies. Cardiovascular Therapeutics, 2019; 9342792.

2. FUNG G, et al. Myocarditis. Circulation Research, 2016; 118(3): 496-514.

3. HEYMANS $S$, et al. The quest for new approaches in myocarditis and inflammatory cardiomyopathy. Journal of the American College of Cardiology, 2016; 68(21): 2348-2364.

4. HUBER SA. Viral myocarditis and dilated cardiomyopathy: etiology and pathogenesis. Current Pharmaceutical Design, 2016; 22(4): 408-426.

5. KANG M, AN J. Viral myocarditis. StatPearls [Internet]. Treasure Island (FL): StatPearls Publishing; 2020. Disponível em: https://www.ncbi.nlm.nih.gov/books/NBK459259/. Acesso em: 10 mar. 2020.

6. MAISCH B. Cardio-immunology of myocarditis: Focus on immune mechanisms and treatment options. Frontiers in Cardiovascular Medicine, 2019; 6:48.

7. MAISCH B, ALTER P. Treatment options in myocarditis and inflammatory cardiomyopathy: Focus on i.v. immunoglobulins. Herz, 2018; 43(5): 423-430.

8. OLEJNICZAK M, et al. Viral myocarditis - incidence, diagnosis and management. Journal of Cardiothoracic and Vascular Anesthesia, 2020; 34:1591-1601.

9. POLLACK A, et al. Viral myocarditis - diagnosis, treatment options and current controversies. Nature Reviews Cardiology, 2015; 12(11): 670-680.

10. ROSE NR. Viral myocarditis. Current Opinion in Rheumatology, 2016; 28(4):383-389.

11. SHAO L, et al. Combination therapy with Coenzyme Q10 and Trimetazidine in patients with acute viral myocarditis. Journal of Cardiovascular Pharmacology, 2016; 68(2): 150-154.

12. SCHULTHEISS HP, et al. Betaferon in chronic viral cardiomyopathy (BICC) trial: Effects of interferon- $\beta$ treatment in patients with chronic viral cardiomyopathy. Clinical Research in Cardiology, 2016; 105(9): 763-773.

13. XU P, et al. Clinical effects of tanshinone IIA sodium sulfonate combined with trimetazidine and levocarnitine in the treatment of AVMC and its effects on serum TNF- $\alpha$, IL-18 and IL-35. Experimental and Therapeitic Medicine, 2018; 16(5): 4070-4074.

14. WANG D, et al. Chinese society of cardiology expert consensus statement on the diagnosis and treatment of adult fulminant myocarditis. Science China. Life Sciences, 2019; 62(2): 187-202.

15. WANG Y, et al. N-Acetyl cysteine effectively alleviates Coxsackievirus B-Induced myocarditis through suppressing viral replication and inflammatory response. Antiviral Research, 2020; 179: 104699. 